\title{
Screening hospital patients for uterine cervical cancer
}

\author{
ELIZABETH HUDSON, SHEILA HEWERTSON, CLIFFORD JANSZ, HARRY GORDON
}

From the Departments of Histopathology, Community Medicine, and Obstetrics and Gynaecology, Northwick Park Hospital and Clinical Research Centre, Harrow, Middlesex, HA1 3UJ

SUMMARY Women patients admitted to a district general hospital with non-gynaecological conditions were offered a cervical smear test. In three years 2296 women were tested. Serious uterine pathology was detected in 13 patients (5.7 per 1000) and significant cytological abnormalities (dyskaryosis of all grades) in $46(20.0$ per 1000$)$. Of the women screened $963(41.9 \%)$ had never had a smear test before and $1608(70.0 \%)$ were over $39 \mathrm{yr}$.

The results show that cervical screening of non-gynaecological patients in hospital reaches many of the women at risk for cervical cancer who do not otherwise have smears taken and reveals considerable uterine pathology.

Screening for preinvasive cancer of the uterine cervix by cervical cytology can be effective in reducing deaths from cervical cancer, ${ }^{12}$ but in England and Wales the results have been disappointing. Nearly 3 million cervical smears are taken annually, but more than half of these are from women under 35 years of age in whom the disease is relatively uncommon. ${ }^{34}$ Macgregors noted that $75 \%$ of women presenting with cervical cancer in Aberdeen had records of previous admission to hospital for conditions which were not obstetric, gynaecological or paediatric. To see if screening of patients in a district general hospital provided a useful preventive measure a programme was started at Northwick Park Hospital in October 1978. The results of the first three years are reported here.

\section{Patients and methods}

In October 1978 a full time health visitor (SH) was appointed under the Community Health Service. She underwent a period of induction and training in the Departments of Obstetrics and Gynaecology, and Cytopathology. This included instruction in the taking of cervical smears and the significance of macroscopic and cytological abnormalities which might be encountered. A pamphlet was included in the papers sent to women patients who were awaiting hospital admission telling them that they would have the opportunity to have a smear taken when they were in hospital. The first four months were taken up with training and gradual involvement of all the wards which were to be included in the

Accepted for publication 26 January 1983 scheme. The health visitor discussed with the ward sister the patients whose medical condition and schedule of investigations or operation permitted an interview and offer of the test. Geriatric, psychiatric and communicable diseases wards were excluded unless a specific request was made by a patient or by the nursing or medical staff. The hospital has 805 beds of which 371 were visited regularly for the screening programme. When the scheme was fully operational it was found sufficient to visit the medical wards twice a week and the surgical wards three times a week in order to see nearly all the admissions. Surgical patients had their cervical smears taken as soon as possible after admission so that it preceded their operation. There was less urgency on medical wards where for example patients with coronary occlusions were not approached until just before they were discharged.

Initially the policy was to screen all women up to the age of $70 \mathrm{yr}$ but this was reduced to $65 \mathrm{yr}$ in the second year of the project because of the high rate of refusal and the more frequent poor health in the older age group. A patient was always given the test if she asked for it, at any age. Women who had never been sexually active were not encouraged to have the test.

The preliminary interview with the patient excluded those women who had had a smear recently and those who were already being screened regularly by their general practitioners, at a clinic or at their place of work. In some cases explanation of the test was time-consuming and ended in its rejection. Patients frequently wished to discuss other problems such as contraception or the menopause. Women who had had a hysterectomy were not 
tested unless there was a relevant problem in which case a vault smear was taken.

If patients were menstruating a smear was not taken in the ward but after the first year of the scheme these women were offered appointments to return for a smear as out-patients. To reduce the risk of false-negative results, patients who had smears taken in the hospital screening programme were sent an appointment to have a second smear taken one year later at one of the district's wellwomen clinics. Subsequently they would be recalled at five-yearly intervals.

The smears were taken from the cervix using a plastic Armovical (Armour Hospital Division, Eastbourne, Sussex) or Rolon (Rocket of London Ltd, Imperial Way, Watford, Herts) spatula. In a few patients in whom the cervix could not be visualised or a speculum could not be passed, a specimen of exfoliated cells was aspirated from the posterior fornix using a glass pipette and bulb or material was collected from the posterior fornix with the blunt end of an Ayre spatula. Ambulant patients were examined on a treatment room couch but others had to be examined in bed.

Abnormal cytology was reported to the consultant under whose care the patient had been admitted, with recommendations for treatment, follow-up or referral for a gynaecologist's opinion. If the cervix had an abnormal appearance or if the patient had significant symptoms, such as postmenopausal bleeding, a gynaecologist was asked to see her even if the smear was negative.

The records of women admitted to the hospital for diagnosis of invasive cervical cancer during the three year period were examined to see if they had had previous hospital admissions for non-gynaecological complaints and might have benefited from a hospital cervical screening service if it had been available.

\section{Results}

During the first three years of the project, from November 1978 to October 1981, 4636 patients were interviewed out of whom 2296 were screened (Table 1). The number screened fell from 861 in the first year to 749 in the second year and to 686 in the third year. This decrease in numbers was partly due to the lowering of the upper age limit from $70 \mathrm{yr}$ to $65 \mathrm{yr}$ in the second year. It was also found in the second and third year that a number of women were readmitted who had been screened during a previous admission.

The largest group of the 2340 women who did not have a smear taken in hospital (Table 2) were the 1121 who had been tested recently as part of a regular screening programme. Of the 2296 women who had smears taken $963(41.9 \%)$ had never to their knowledge been screened before. This proportion increased with age as shown in Table 3 . The largest group screened were between 50 and $59 \mathrm{yr}$ and $1608(70.0 \%)$ were over $39 \mathrm{yr}$. Of the 225 women who refused the test, 150 were over $60 \mathrm{yr}$.

Table 1 Hospital patients who were offered a cervical smear test

\begin{tabular}{llc}
\hline Year & Patients interviewed & Patients screened \\
\hline 1 & 1730 & $861(49 \cdot 8 \%)$ \\
2 & 1542 & $749(48 \cdot 6 \%)$ \\
3 & 1364 & $686(50 \cdot 3 \%)$ \\
Total & 4636 & $2296(49.5 \%)$ \\
\hline
\end{tabular}

Table 2 Patients who were not screened in hospital

\begin{tabular}{|c|c|}
\hline Reason & Number (\%) \\
\hline $\begin{array}{l}\text { Had a recent smear test } \\
\text { Refused the test } \\
\text { Hysterectomy } \\
\text { Not sexually active } \\
\text { Menstruating* } \\
\text { Language problem } \\
\text { Advice given only } \\
\text { No opportunity to take a smear } \\
\text { Examination unsuccessful } \dagger \\
\text { Total }\end{array}$ & $\begin{array}{r}1121 \\
225 \\
340 \\
347 \cdot 9) \\
160 \\
14 \cdot 5 \\
132 \\
39.8 \\
39 \\
42 \\
5 \cdot 6) \\
243 \\
3.7 \\
38 \\
10 \cdot 8) \\
2340\end{array}$ \\
\hline
\end{tabular}

*76 of the women who were menstruating while in hospital were $D$ offered an out-patient appointment to have a smear taken. Of these 35 returned for a smear.

†These women consented to have a smear taken but did not permit $N$ the examination to be completed.

Table 3 Screening related to age of patients

\begin{tabular}{|c|c|c|c|c|c|}
\hline Age (yr) & Interviewed & Screened & $\begin{array}{l}\text { Screened for } \\
\text { first time }\end{array}$ & $\begin{array}{l}\text { Positive cytology } \dagger \\
\text { (rate per } 1000 \text { screened) }\end{array}$ & Refused screening \\
\hline $\begin{array}{l}\text { Teenage } \\
20-29 \\
30-39 \\
40-49 \\
50-59 \\
60-69 \\
70 \text { \& over } \\
\text { Total }\end{array}$ & $\begin{array}{l}177 \\
648 \\
826 \\
911 \\
995 \\
884 \\
195 \\
4636\end{array}$ & $\begin{array}{r}41 \\
249 \\
398 \\
476 \\
524 \\
491 \\
117 \\
2296\end{array}$ & $\begin{array}{r}32(78.0 \%) \\
84(33.7 \%) \\
81(20.4 \%) \\
150(31.5 \%) \\
220(42.0 \%) \\
309(62.9 \%) \\
87(74.4 \%) \\
963(41.9 \%)\end{array}$ & $\begin{array}{l}0(0) \\
1 \\
2 \\
2(5 \cdot 0) \\
4(8 \cdot 4) \\
1 \\
3 *(1 \cdot 9) \\
0(6 \cdot 1) \\
0(0) \\
11(4 \cdot 8)\end{array}$ & $\begin{array}{r}1 \\
16 \\
9 \\
13 \\
36 \\
115 \\
35 \\
225\end{array}$ \\
\hline
\end{tabular}

* 2 invasive squamous carcinomas, stages IIA and IB and 1 endometrial carcinoma.

†8 patients with positive cytology had not had a smear test before. 
Dyskaryosis was found in the smears of 46 women. In addition two post-menopausal patients were referred for a gynaecologist's opinion in spite of negative cytology because the health visitor had elicited a history or saw evidence of postmenopausal bleeding. Both these women had endometrial carcinoma. The total of 48 women with significant findings is 1 in 47 women screened, a rate of 21 per 1000 . There were 11 patients who had severe dyskaryosis (positive smears). Biopsies of these showed severe dysplasia (4), carcinoma in situ (3), invasive squamous carcinoma (2) and endometrial adenocarcinoma (1). One patient has not yet had a biopsy. Mild dyskaryosis present in 35 women was an indication for follow-up and has progressed to severe dyskaryosis in one patient so far. Incidental findings in the smears such as trichomoniasis (55), candidiasis (39) or actinomyces like organisms in women with intrauterine contraceptive devices (2) were indications for treatment if the patients had symptoms. Patients with cervical polypi (40) uterine prolapse (32) post-menopausal bleeding (4) and clinically suspicious cervix (3) were referred for gynaecological advice.

During the three-year period of this study 37 women had presented to the gynaecology unit with invasive cervical cancer. Twelve of these patients were sent on without biopsy to neighbouring hospitals which have radiotherapy units and detailed case records were not available. The other 25 were admitted for biopsy and their hospital notes showed that $12(48 \%)$ of them had been in hospital previously for non-gynaecological complaints. Ten of these 25 women had no record of previous hospital admission but three of them had been to hospital as outpatients. There was no information available about the remaining three patients.

\section{Discussion}

The reduction in clinical invasive carcinoma of the cervix achieved by cervical screening is proportional to the percentage of the female population screened. ${ }^{1}$ However, the success of even the most comprehensive screening programmes has been limited by the disproportionately high incidence of the disease in the group of women who do not attend clinics where cervical smears are taken routinely and who tend not to respond to personal invitations to be screened. This is well illustrated in the Grampian Region of Scotland where there have been 115 deaths from cancer of the cervix between 1973 and 1978 in a population where more than $95 \%$ of the women at risk have been screened. ${ }^{6}$ Only $9(8 \%)$ of the women who died of the disease had had a smear test. Further progress in prevention of cervical cancer depends on the identification and screening of the women who have never had a cervical smear.

In England and Wales there has been a fall in deaths from cancer of the cervix in women between the ages of 45 and $55 \mathrm{yr}$ and to a lesser extent between 35 and $45 \mathrm{yr}^{3{ }^{34}}$ This is thought probably to reflect the large number of smears (more than $50 \%$ ) taken from women under $35 \mathrm{yr}$ compared with the number taken from women over $35 \mathrm{yr}$ in whom $94 \%$ of deaths from the disease occur. ${ }^{4}$ The young women are screened when they attend for family planning and for antenatal care. In the absence of a screening programme based on invitations to women to come for screening the attendance of women in the middle and older age groups is haphazard and fragmentary. Further encouragement is necessary to screen these older women. There is awareness of the high risk of the disease in women who attend clinics for sexually transmitted diseases, in women in prison and in women who have already had an abnormal smear. The presence of a population containing many unscreened women and a significant number at risk for cancer of the cervix in the non-gynaecological wards of general hospitals is less well known although there are reports in the literature from several countries all of which demonstrate the benefit of screening hospital patients. $^{7-12}$

In this study 2296 women have had a cervical smear test while patients in Northwick Park Hospital. Nine hundred and sixty three $(41.9 \%)$ had not to their knowledge had a previous test and 766 $(33.4 \%)$ of these were aged 40 yr or more. This is an indication of the number of unscreened women who will agree to be tested while in hospital. Eleven patients had positive cervical smears. Biopsy showed severe dysplasia, carcinoma-in-situ or invasive squamous carcinoma of the cervix in nine and endometrial carcinoma in one patient. The one remaining patient is awaiting biopsy. Serious uterine pathology detected from cervical smears in 4.8 per 1000 compares with 1.2 per 1000 over the same three-year period at the well-women clinics in Harrow district for which Northwick Park is the district general hospital, and with 5.4 per 1000 found by Duncan and Parker in a similar programme at Wellington Hospital, New Zealand. ${ }^{12}$ National figures for positive smears average between 4 and 6 per $1000^{4}$ but in Harrow where $67.4 \%$ of the economically active residents are in professional or other non-manual occupations there is not a high incidence of cervical cancer. Two patients were referred for curettage because a history of post-menopausal bleeding was elicited; both had endometrial carcinoma. Their cytology was 
negative but the early detection of their tumour was a direct result of the screening programme and brings the number of patients with serious uterine pathology to 13 , that is 5.7 per 1000 . The 35 patients with mild dyskaryosis will be followed up as they are at high risk of progressing to a more severe lesion. One already has severe dyskaryosis. Significant cytological abnormalities which included positive smears and mild dyskaryosis were present in 46 women $(20.0$ per 1000$)$ which is an acceptable ratio for a screening programme of this kind.

Screening of hospital patients may reveal uterine pathology in women who already have a serious illness with a poor prognosis. The 11 patients with positive smears in this study were all thought likely to benefit from the finding. In comparable programmes for screening hospital patients, Duncan and Parker $^{12}$ estimated that $12.5 \%$ of patients with abnormal smears did not have their expectation or quality of life improved by the finding and $\mathrm{Du}$ Toit and van Niekerk ${ }^{10}$ in South Africa estimated that $16 \%$ of their patients were already too ill to benefit. In this programme consultation with the ward sister before offering patients a smear test ensured that women with advanced malignant or other disease were not screened.

The success of the hospital screening programme has depended on careful planning and on the interviewing skill of the health visitor which have ensured the co-operation of the medical and nursing staff on the wards. The health visitor required considerable perseverance to go back, sometimes several times to get a suitable opportunity to interview or examine a certain patient without interfering with other investigations and treatment. Explanation of the test was often time-consuming but there was an advantage in being able to take the test immediately after consent had been obtained. In a district with a large immigrant Asian community there were many patients who did not speak English in which case an interview was arranged if possible when a close relative was present to interpret. The cost of the programme consisted of the health visitor's salary and equipment. The screening could have been done by a trained nurse or midwife, possibly part-time, but motivation and thorough training in smear taking and in gynaecological symptomatology are essential for good results. The $600-800$ smears taken annually were absorbed by the hospital cytology laboratory which serves the health district without the need of extra staff.

During the three years of this study only 37 patients were referred to the Department of Obstetrics and Gynaecology with clinical cancer of the cervix. This small number may partially reflect the relatively low risk of the disease in a prosperous suburban population but it may also be due to the absence of a radiotherapy department at the hospi- 을 tal resulting in direct referral by general practitioners of an unknown number of patients from the health district to other hospitals where the treatment is available. Twelve of the 25 patients with the disease who were admitted to Northwick Park Hospital $\overrightarrow{\widetilde{\sigma}}$ for biopsy had been in hospital previously and it is $\varrho$ reasonable to suppose that some of them would के have had their condition detected at a preinvasive $\overrightarrow{0}$ stage if cervical smears had been taken at that time. $\overrightarrow{\vec{H}}$

The decrease in the number of women screened in $\vec{\omega}$ successive years of the scheme is partly due to the readmission of patients who had been screened on a ? previous admission. Probably it also reflects the increasing number of women who are being screened by their general practitioners and at clinics. In a community where screening is offered by direct $\mathrm{O}$ invitation the screening of hospital patients becomes unnecessary. Two reports from North America ${ }^{13}{ }^{14} \vec{c}$ describe successful programmes for screening women who attend hospital as out-patients. At Northwick Park screening has already been success- $\overrightarrow{\mathscr{O}}$ fully extended to women staff.

Three years experience of screening women patients in the non-gynaecological wards of a district general hospital by cervical cytology has shown that sufficient significant pathology is detected to justify the recommendation of hospital screening on $\mathrm{a} \stackrel{\square}{\AA}$ wider scale in Great Britain. ${ }^{15}$ Women who have $\vec{\overrightarrow{ }}$ never had a smear and women between 40 and $60 \mathrm{yr} \frac{}{3}$ are particularly well represented among those who accepted screening while in hospital. These women are reluctant to come to clinics where cervical smears are taken routinely and high rates for cervi-? cal cancer can be expected among them. ${ }^{3}$

We wish to thank the consultants at Northwick Park Hospital for allowing their patients to be included in the screening programme.

\section{References}

1 Miller AB, Lindsay J, Hill GB. Mortality from cancer of the uterus in Canada and its relationship to screening for cancer of $O$ the cervix. Int J Cancer 1976;17:602-12.

${ }^{2}$ Clarke EA, Anderson TW. Does screening by Pap smears help to prevent cervical cancer? A case-control study. Lancet $\mathbb{\&}$ 1979;ii: $1-4$.

${ }^{3}$ Draper GJ. Screening for cervical cancer: revised policy. The $\square$ recommendations of the DHSS Committee on gynaecological cytology. Health Trends 1982;14:37-40.

4 Roberts A. Cervical cytology in England and Wales, 1965-80. Health Trends 1982;14:41-3.

${ }^{5}$ Macgregor JE. Timing of cervical smears. Br Med J 1977;1:774.

- Macgregor JE. In: Taking uterine cervical smears. Aberdeen: British Society for Clinical Cytology, 1981. 
${ }^{7}$ Greenwald P, Nasca PC, Gordon ED. Prevention of cervix cancer deaths through hospital screening. NY State J Med 1972;72:742-5.

${ }^{8}$ Wachtel E, Wycherley J, Lee CN. Screening for cancer of the female genital tract in general medical and surgical wards. Practitioner 1972;208:505-8.

Sargeant EJ, Qizilbash AH, Johnson FL. Cervical cytology screening: experience of a general hospital. Can Med Assoc J 1977;117:1026-7.

${ }^{10} \mathrm{Du}$ Toit JP, Van Niekerk WA. Cervical cytologic screening among females with non-gynecologic hospital admissions. Obstet Gynecol 1978;51:342-6.

" Boyce J, Fruchter R, Thompson M, et al. Cervical cancer screening. $N Y$ State J Med 1981;81:331-3.

12 Duncan GR, Parker RE. Cervical cytological screening of non- gynaecological female hospital inpatients. Aust NZJ Obstet Gynaecol 1981;21:113-5.

${ }^{13}$ Fruchter RG, Boyce J, Hunt M. Missed opportunities for early diagnosis of cancer of the cervix. Am J Public Health 1980;70:418-20.

14 Kizilbash M, Mettlin C. Pap Smears: Access to hospital outpatients of non-gynecological services. J Surg Oncol 1981;18:143-6.

is Editorial: Screening for cervical cancer. Br Med J 1976;ii:65960.

Requests for reprints to: Dr Elizabeth Hudson, Department of Histopathology, Northwick Park Hospital and Clinical Research Centre, Watford Road, Harrow, Middlesex, HA1 3UJ, England. 